\title{
Improvement of the Optical Properties of Sandblasted Glass by Depositing Acrylic Coatings
}

\author{
Mostafa Kolli ${ }^{1, *}$, Hind Laouamri ${ }^{2}$, Noureddine Bouaouadja ${ }^{2}$ \\ ${ }^{1}$ Emerging Materials Research Unit, Ferhat Abbas University Setif 1, Algeria \\ ${ }^{2}$ Laboratory of Non Metallic Materials, IOMP, Ferhat Abbas University Setif 1, Algeria
}

Copyright $(\subset 2015$ by authors, all rights reserved. Authors agree that this article remains permanently open access under the terms of the Creative Commons Attribution License 4.0 International License

\begin{abstract}
In their different applications in Saharan regions, ordinary glass products (glazes, cars windshields, solar panels protecting glass etc.) are exposed to inevitable sandblasting effect caused by frequent sandstorms. The surface flaws induced by sand particle's impact lead to a deterioration of the glass strength and optical transmission. In this work, the effect of acrylic coatings on the optical properties of sandblasted glass is established. After that, the effect of subsequent sandblasting on the coated glass is studied. Obtained results show that sandblasting causes a considerable drop in the optical transmission (from $91.5 \%$ to 14.6\%). Depositing acrylic coatings allows increasing significantly the optical transmission $(\sim 87 \%)$. Under the subsequent sandblasting, the optical transmission of the coated glasses falls from its initial value $(\mathrm{T}=87 \%)$ to approximately $22 \%$, which is somewhat better than the transmission of the sandblasted glass $(\mathrm{T}=14.6 \%)$.
\end{abstract}

Keywords Acrylic Coatings, Sandblasting, Optical Transmission, Strength, Glass

\section{Introduction}

In their different applications in Saharan regions, ordinary glass products (glazes, cars windshields, solar panels protecting glass etc.) are exposed to inevitable sandblasting effect causing the deterioration of the glass strength and optical transmission [1-4].

In recent years, considerable effort has been devoted to remedy to sandblasting deleterious effects [1,5-8]. Preventive treatments have been proposed[1,5] to strengthen the glass surface. They consist of introducing residual compressive stress at the surface layers by thermal tempering or ion exchange [9]. These approaches present however some shortcomings: The thermal tempering process tends to distort the glass surface and the ion exchange is very slow process that requires the use of expensive products. Moreover, the fact that both processes require high temperatures leads to significant energy costs $[9,10]$. Besides, the strengthened glass by surface compression is not completely protected against subsequent sandblasting effects [1]. For all these reasons, corrective approaches have emerged as a more realistic way to strengthen glass.

Deposition of coatings is more attractive economically and technically in strengthening damaged glasses $[9,11]$. In addition to the mechanical strengthening [10-16], other additional optical or hydrophobic attributes can be acquired [9]. Among the known deposition techniques, spraying technique shows several advantages. It is an easy and rapid process that can be executed on large surfaces and on locally installed glass without dismantling.

In the present work, the effect of acrylic coatings on the optical properties of sandblasted glass is investigated. For the sustainability of the coated glass, the effect of the subsequent sandblasting on the acrylic coating was also investigated.

\section{Experimental Procedure}

\subsection{Used Materials}

\subsubsection{Soda-lime glass}

In this work, a soda-lime glass sheet of $3 \mathrm{~mm}$ thickness is used. The mean chemical composition and the main physical and mechanical characteristics are given in Tables 1 and 2.

Table 1. Mean chemical composition of the used glass.

\begin{tabular}{cccccccc}
\hline Oxides & $\mathrm{SiO}_{2}$ & $\mathrm{CaO}$ & $\mathrm{Na}_{2} \mathrm{O}$ & $\mathrm{MgO}$ & $\mathrm{Al}_{2} \mathrm{O}_{3}$ & $\mathrm{Fe}_{2} \mathrm{O}_{3}$ & Others \\
\hline $\begin{array}{c}\% \\
\text { Mass }\end{array}$ & 73.12 & 10.5 & 9.40 & 2.32 & 4.62 & 0.009 & - \\
\hline
\end{tabular}

Table 2. Glass main physical and mechanical characteristics.

\begin{tabular}{cc}
\hline Characteristic (unit) & Value \\
\hline Density $\left(\mathrm{g} / \mathrm{cm}^{3}\right)$ & 2.45 \\
\hline Young's Modulus $(\mathrm{GPa})$ & 75 \\
\hline Poisson's ratio & 0.22 \\
\hline Strength by biaxial bending test $(\mathrm{MPa})$ & 80 \\
\hline Refractive index & 1,5182 \\
\hline Transition temperature $\left({ }^{\circ} \mathrm{C}\right)$ & 510 \\
\hline
\end{tabular}




\subsubsection{Acrylic resin}

For coating the sandblasted glass, an acrylic resin (Max Meyer, Ref 1.360.0500, France) is used. This acrylic resin is transparent in the visible range and its refractive index, measured by Abbe's refractometer, is equal to 1,5172. This value is very close to that of glass $(1,5182)$. Optically, this resin is a favourable choice for soda-lime glass coating. In addition to the acrylic resin, an extra fast cross-linking agent (Max Meyer 8000) was used. To adjust for an appropriate fluidity, the prepared mixture is diluted by using a thinner (Max Meyer 4310, France) added to the mix.

\subsection{Sample Preparation}

Glass samples square shaped $\left(50 \times 50 \times 3 \mathrm{~mm}^{3}\right)$ were cut from the same glass sheet. They were submitted to sandblasting tests (section 2.3). In a previous work [7], it was noticed that HF-etching of sandblasted glass can enhance optical transmission. To investigate the combined effect of HF etching/ acrylic coating, a batch of sandblasted samples was etched by immersion in a solution of hydrofluoric acid (HF 5\%) for different durations (2, 30, $60 \mathrm{~min}$ ). The chemical etching occurs at ambient temperature and atmospheric pressure under magnetic stirring of the solution.

All samples (etched or not etched) were coated with one or two acrylic layers. To study the resistance of the acrylic coating to the subsequent sandblasting, the coated samples were subjected to second sandblasting tests.

\subsection{Sandblasting Tests}

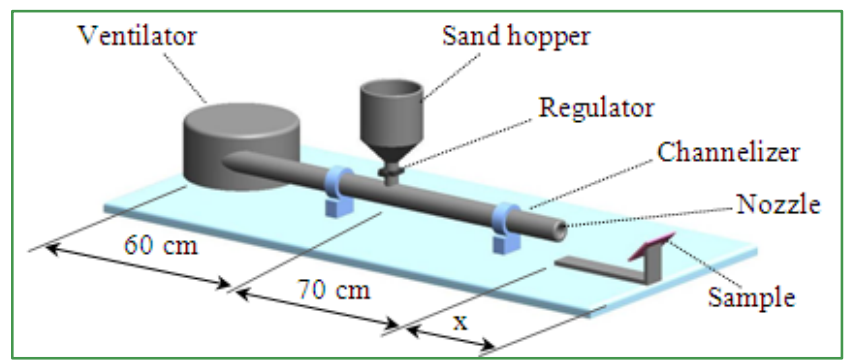

Figure 1. Scheme of the used sandblasting apparatus (x: adjustable distance).

For the sandblasting tests, a horizontal blower apparatus (Figure 1) was used. It is equipped with the following components:

- A ventilator for creating an air flow which carries the sand throughout the channelizing tube.

- A sand hopper provided with a flow regulator.

- An adjustable sample holder $\left(\alpha=0-90^{\circ}\right)$.

More details of the sandblasting apparatus are given in a previous work [17]. It is a horizontal jet impingement system as recommended by the standards for airborne particles erosion testing (ASTM G76192020-21) [18]. The tests are carried out using a stationary target exposed to a flux of sand particles accelerated in an air stream by a ventilator.
The sand used in sandblasting experiments is natural sand coming from the region of Ouargla (South of Algeria). It is characterized by a very high Vickers micro-hardness $(\mathrm{Hv}=$ $14.49 \pm 3.28 \mathrm{GPa}$ ) justifying the high damaging effects of its grains on the glass surface [1].

During sandblasting experiments, the following experimental parameters were fixed:

- Sand mass: $\mathrm{m}=200 \mathrm{~g}$.

- Impact angle: $\alpha=90^{\circ}$.

- Distance nozzle-sample: $\mathrm{x}=50 \mathrm{~mm}$.

- Sand flow rate: $r=1.25 \mathrm{~g} / \mathrm{s}$.

- Projection velocity: $\mathrm{V}=20 \mathrm{~m} / \mathrm{s}$.

These parameters lead to a strongly deteriorated state, as was found in preliminary tests, which enables to better detect any improvement on the glass properties after coating. The sandblasted samples were carefully cleaned with acetone and stored in hermetically sealed bags to be, thereafter, coated by acrylic resin.

\subsection{Coating Procedure}

Coatings deposition was carried out by spraying the prepared solution by means of a nozzle under compressed air (air compressor NFBX, 200L, $\mathrm{P}_{\max }=11$ bars). The solution was prepared by diluting $100 \mathrm{ml}$ of the acrylic resin in $50 \mathrm{ml}$ of the thinner. The hardener $(30 \mathrm{ml})$ was added to the solution and the combined mixture was stirred for $2 \mathrm{~min}$. The solution was then sprayed on the sandblasted side of the substrate vertically oriented to the spraying flow, under a pressure of 4 bars. The distance between the gun nozzle and the substrate surface was kept constant for all tests and equal to $40 \mathrm{~cm}$. The procedure followed to deposit the second coating was the same as that followed to deposit the first one. The second spraying operation was executed approximately 2 min after the first one.

The coated samples were dried in a dust-free environment for approximately one hour and then treated in the oven at $150{ }^{\circ} \mathrm{C}$ for 3 hours.

\subsection{Characterization}

The optical transmission of all obtained samples was carried out by means of a microdensitometer (MD100 Carl Zeiss Jena) using a light mean wavelength of $550 \mathrm{~nm}$ with normal incidence.

The erosion rate (Er), defined as the rate of material mass removal against the mass of the projected sand, was determined by weighing the coated samples, before and after sandblasting. It was calculated as follows:

$$
\mathrm{Er}=\left(\mathrm{m}_{1}-\mathrm{m}_{2}\right) / \text { mass of impacting particles }[\mathrm{g} / \mathrm{g}]
$$

- $\quad-\mathrm{m}_{1}$ : mass of the coated glass before sandblasting.

- $\quad-\mathrm{m}_{2}$ : mass of the coated glass after sandblasting.

\section{Results and Discussion}




\subsection{Optical Transmission}

Figure 2 shows the optical transmission of uncoated, single coated and double coated sandblasted glasses. The HF $(5 \%)$ etching on the sandblasted glass was carried out for 2 , 30 and 60 min etching durations before coating. The results on uncoated sandblasted samples show the low efficiency of HF treatment to improve the optical transmission. It decreases from its initial value of the sandblasted glass $(14.6 \%)$ to less than $9 \%$ after just two minutes of treatment. This decrease in the optical transmission was interpreted by M. Kolli et al. [7,8] by median cracks grooving and lateral cracks chipping phenomena. These two phenomena generate more surface irregularities which cause increased light scattering and therefore decreased optical transmission. After that, the optical transmission undergoes a slight increase due to the decrease of the differences between the hollows and crests of the surface irregularities. The optical transmission measured after one hour of attack $(16.7 \%)$ is almost in the same order of the optical transmission of the sandblasted glass $(14.6 \%)$, but remains significantly lower than that of the as-received state $(91.5 \%)$.

After depositing the first acrylic coating, a significant improvement in optical transmission was recorded. For the non-etched sandblasted glass, the optical transmission reaches $87 \%$. The deposition of the second acrylic coating seems to have a small additional effect on the optical transmission ( $89 \%$ for the non-etched sandblasted glass). In fact, the first coating (Thickness $\sim 28 \mu \mathrm{m}$ ) is able to fill the surface asperities having a lower roughness magnitude $(\mathrm{Rt}=$ $18.475 \mu \mathrm{m})$. In addition, the optical homogeneity of the set (coat + substrate) provided by the similar refractive index limits the light scattering. Accordingly, the optical transmission reaches high levels after the first coat.

It is also noted that the optical transmission of the coated glass did not reach the optical transmission of the as-received glass $(91.5 \%)$. This is due to the probable adhesion of dust particles on the coating during curing, imperfect filling of surface roughness and non-perfect state of the outer surface of the deposited coating.

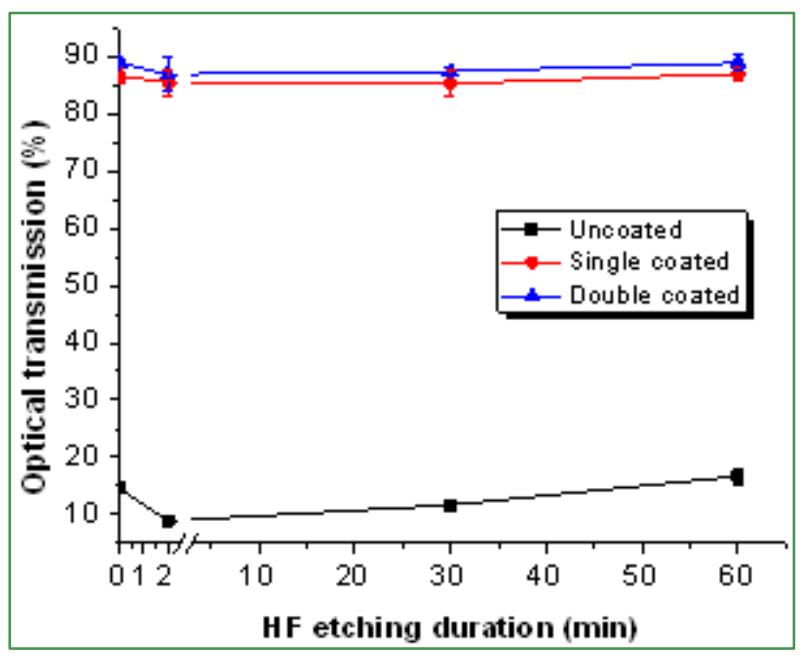

Figure 2. Optical transmission according to the HF etching durations.

\subsection{Erosion Behaviour of the Coated Glass}

Since that the use of acrylic coating favoured the restitution of the optical properties of the sandblasted glasses so the study of the sustainability of these coatings when exposed to a subsequent sandblasting is of great importance. In Figure 3, it is showed the appearance of the acrylic coating after sandblasting. It was observed that sandblasting damage on the coating was regular on the totality of the examined area. The major occurring defects are localized plastic deformation, chipping or scratch resulting from successive and interactive sand grains impacts.

The erosion rate of the acrylic coating was evaluated on the coated glass. Figure 4 shows its change depending on the angle of sandblasting. The erosion rate increases sharply from $2.5 \times 10^{-6} \mathrm{~g} / \mathrm{g}$ at $15^{\circ}$ angle to $46 \times 10^{-6} \mathrm{~g} / \mathrm{g}$ for $25^{\circ}$. After that, it drops dramatically to $10.5 \times 10^{-6} \mathrm{~g} / \mathrm{g}$ at $\alpha=30^{\circ}$ and continued to decrease but less significantly up to the angle $45^{\circ}$. Beyond that, it stabilizes at approximately $2.10^{-6} \mathrm{~g} / \mathrm{g}$.

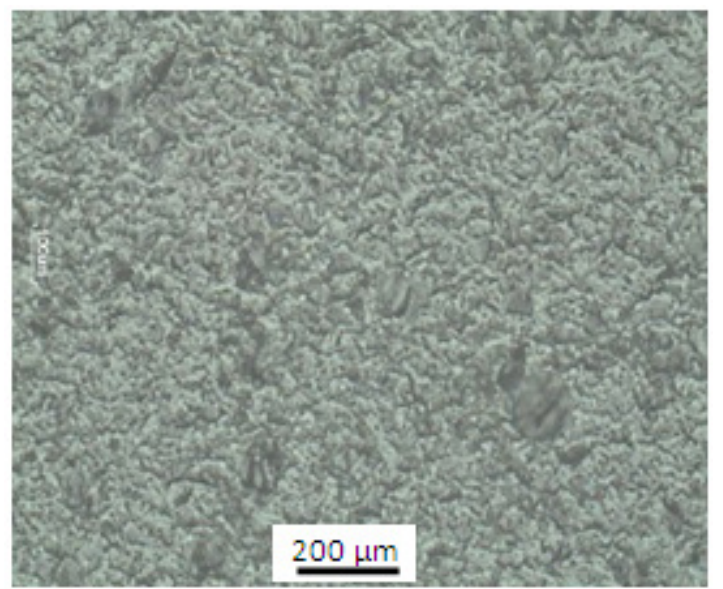

Figure 3. Surface appearance of the coated glass after sandblasting.

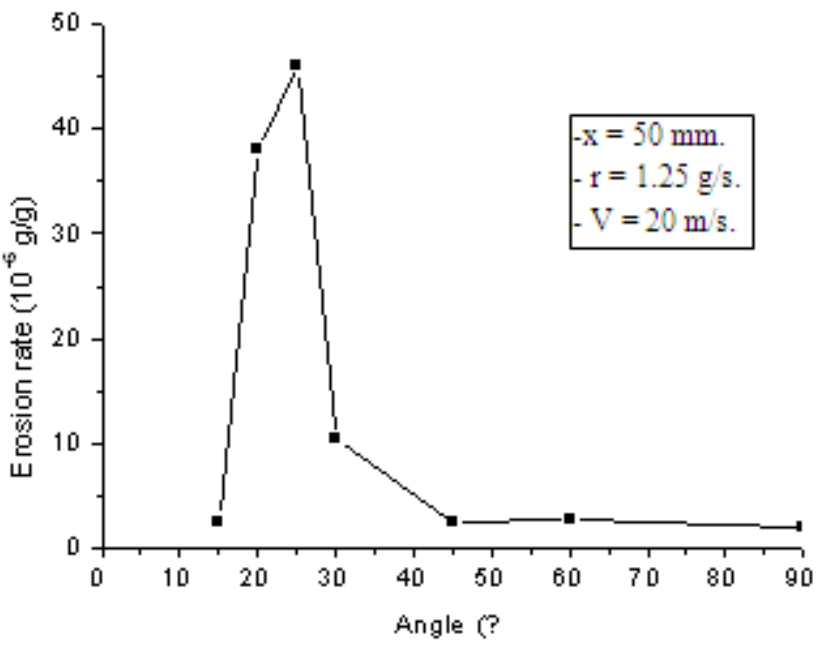

Figure 4. Erosion rate evolution depending on the angle (sandblasting mass $=200 \mathrm{~g}$ ).

Erosive wear behaviour of materials, in general, could be classified into two distinct modes of material removal, 
namely, "ductile" erosion and "brittle" erosion. For the ductile mode the erosion loss peaked at particle impingement angle of $20^{\circ}$ to $30^{\circ}$, while brittle erosion was typically characterized by an erosion maximum in the vicinity of $90^{\circ}$ impingement. For our coating material (acrylic resin) the erosion rate takes its maximum at the angle $25^{\circ}$ which characterizes the ductile erosion behaviour.

The following sections present the effect of the projection angle and the sand mass on the optical transmission of the sandblasted coated glasses.

\subsection{Angle Effect}

Figure 5 shows the variation of the optical transmission versus the sandblasting angle for a sand mass of $200 \mathrm{~g}$ using a projection velocity of $25 \mathrm{~m} / \mathrm{s}$. From this figure, it can be noticed that the optical transmission drops dramatically at the angle $30^{\circ}(\mathrm{T}=25 \%)$. After that it continues to decrease until $60^{\circ}$ angle, but very slightly $(\mathrm{T}=22 \%)$. From $60^{\circ}$, it receives a slight increase with the sandblasting angle to achieve $\mathrm{T}=32 \%$ at $90^{\circ}$. This implies that from optical transmission point of view, the more defective angle is not $25^{\circ}$ which is the more defective from erosion rate point of view, but it ranges from 30 to approximately $60^{\circ}$. The loss in the optical transmission is mainly attributed to the scattering of light which itself depends on the surface defects. The impact angle of $25^{\circ}$ leads to the maximum material removal but not the most damaged surface state allowing maximum light scattering which can be achieved between $30^{\circ}-60^{\circ}$.

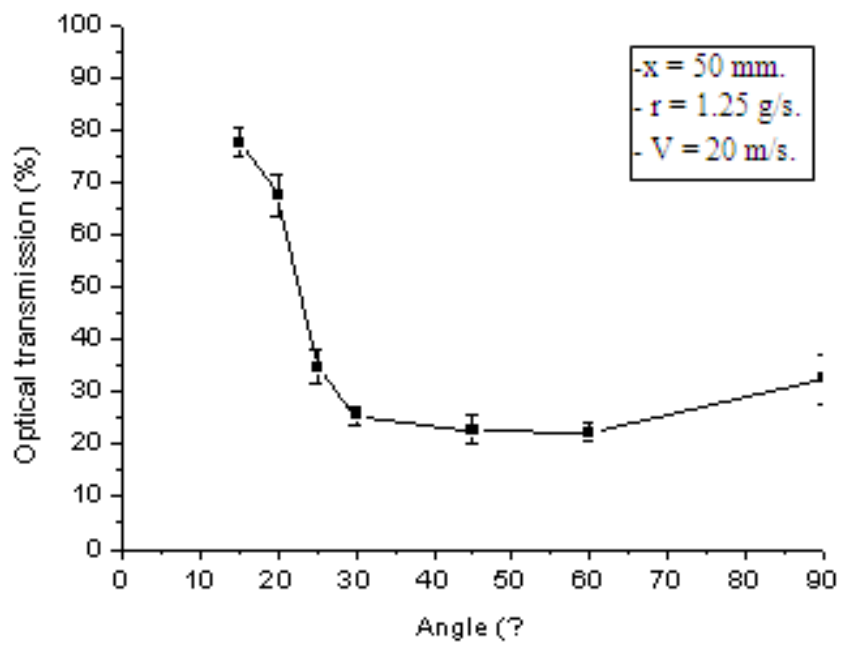

Figure 5. Optical transmission versus sandblasting angle ( sand mass $=200$ g).

\subsection{Mass Effect}

Figure 6 shows the variation of the optical transmission as a function of the mass of the projected sand for a projection angle of $45^{\circ}$ (more defective angle for the coated glass, see Figure 5). From this figure, it can be observed that the optical transmission decreases regularly from $44 \%$, corresponding to $20 \mathrm{~g}$ sand mass, to approximately $22 \%$ corresponding to $150 \mathrm{~g}$ sand mass. With a sand mass more than $150 \mathrm{~g}$, no additional defective effect can be noticed (the sample is completely damaged). This means that the damage threshold (maximum damage) is reached at $150 \mathrm{~g}$ projected sand mass.

Earlier study [19] on the effect of sand mass on the optical transmission of sandblasted glass $\left(\alpha=90^{\circ}\right)$ shows that there are two major steps: A sharp decrease up to a minimum value ( $\sim 15 \%$ at $150 \mathrm{~g}$ sand mass) followed by a nearly constant level "plateau". The drop in the optical transmission noticed for the coated glass ( $\mathrm{T} \sim 22 \%$ ), after sandblasting, is not shocking because no material (including glass substrate) can prevent erosion effect. Moreover, the optical transmission recorded for the sandblasted glass $(14.6 \%)$ is lower than that recorded for the coated glass sandblasted in the same conditions (22\%).

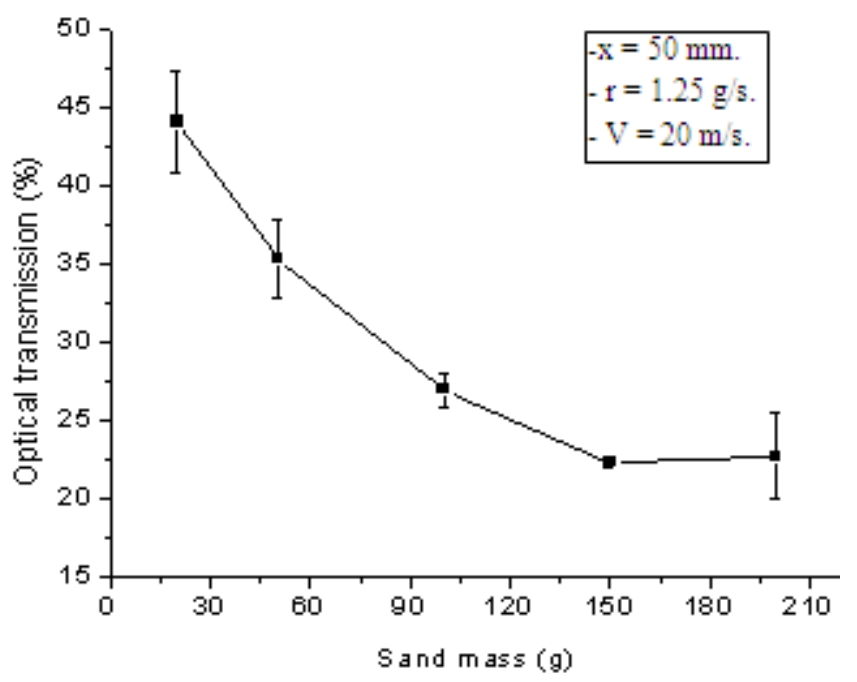

Figure 6. Variation of the optical transmission as a function of the sandblasting mass for a projection angle of $45^{\circ}$.

\section{Conclusions}

Throughout the obtained results, it can be concluded that:

- Depositing acrylic coatings on a sandblasted soda-lime glass improve substantially the optical transmission.

- The deposition of a second acrylic coating has a small additional effect on the optical transmission.

- The previous HF-etching treatment shows no significant effect on the optical transmission.

- The deposited coating has an erosion behaviour characterizing ductile materials (the erosion rate reaches its maximum at $25^{\circ}$ ).

- After the subsequent sandblasting, the coated glass loses its acquired optical performance. The optical transmission falls from its initial acquired value $(\mathrm{T}$ $87 \%$ ) to approximately $\mathrm{T}=22 \%$ which is somewhat better than the transmission of the uncoated sandblasted glass $(\mathrm{T}=14.6 \%)$. 


\section{REFERENCES}

[1] C. Bousbaa, A. Madjoubi, M. Hamidouche and N. Bouaouadja, Effect of annealing and chemical strengthening on soda lime glass erosion wear by sand blasting, Journal of the European Ceramic Society, 23 (2003), 331-343

[2] M. A. Madjoubi, C. Bousbaa, M. Hamidouche and N. Bouaouadja, Weibull statistical analysis of the mechanical strength of a glass eroded by sand blasting, Journal of the European Ceramic Society, 19 (1999), 2957-2962

[3] N. Bouaouadja, S. Bouzid, M. Hamidouche, C. Bousbaa, and M. Madjoubi, Effect of sandblasting on the efficiencies of solar panels, Applied Energy, 65 (2000), 99-105

[4] N. Pronk, B. Fildes, M. Regan, M. Lenné, N. Truedsson and T. Olsson, Windscreens and Safety: A Review, Accident research centre, Monash University, Report N 183, January 2006

[5] N. Bouaouadja, M. Madjoubi, M. Kolli, C. Bousbaa, M. Hamidouche, Etude des possibilités d'amélioration de la transmission optique d'un verre sodocalcique érodé par sablage, Verres, Céramiques \& Composites, 1 (2011), 43-51

[6] N. Bouaouadja, C. Bousbaa, T. Mahdaoui, H. Laouamri, M. A. Madjoubi, Improvement of the optical transmission of an eroded soda lime glass by PVB and PES coatings, Proceedings of the JMSM 2008 conference, Physics Procedia, 2 (2009), 1351-57

[7] M. Kolli, M. Hamidouche, N. Bouaouadja, G. Fantozzi, HF etching effect on sandblasted soda-lime glass properties, $J$. Eur. Ceram. Soc., 29 (2009), 2697-2704

[8] M. Kolli, M. Madjoubi, M. Hamidouche, N. Bouaouadja, G. Fantozzi, Amélioration de la résistance mécanique et de la transmission optique d'un verre sablé par traitement chimique à l'acide fluorhydrique, Ann. Chim-Sci.Mat., 35 (2), (2010), 129-136

[9] M. Wen, J-M. Chabagno, G. Silverman, M. Bourrel, Edge-strengthening of flat glass with acrylate coatings, $J$. Non-Cryst. Solids, 354 (2008), 5060-5067
[10] S.W. Carson, V.D. Papanu, Improved mechanical performance of flat glass components through application of strength-increasing coatings, J. Non-Cryst. Solids, 218 (1997), 169-173

[11] T. El-Sayed, R. J. Hand, Modelling the strengthening of glass using epoxy based coatings. J. Eur. Ceram. Soc., 31 (2011), 2783-2791

[12] J. Teisseire, D. Dalmas, S. Lohou, C. Da Silva, E. Barthel, Glass strengthening by polymeric coatings: combined effect of mechanical properties and confinement, Int. J. Fracture, 170 (2011), 115-121

[13] R.J. Hand, B. Ellis, B.R. Whittle, F.H. Wang, Epoxy based coatings on glass: strengthening mechanisms, J. Non-Cryst. Solids, 315 (2003), 276-287

[14] L. Nikolic, L. Radonjic, Effect of the Silica Sol-Gel Coatings on the Properties of Glass Substrate, Ceram. Int., 24 (1998), $547-552$

[15] K. Endres, M. Mennig, M. Amlung, A. Gier, H. Schmidt, Enhancement of fracture strength of cutted plate glass by the application of $\mathrm{SiO}_{2}$ sol-gel coatings, Thin Solid Films, 351 (1999), 132-136

[16] G. de With, R.H. Brzesowsky, J.G. van Lierop, I.J.M. Snijkers-Hendrickx, N.A.M. Sweegers, Strengthening of glass by hybrid organic-inorganic coatings, J. Non-Cryst. Solids, 226 (1998), 105-113

[17] S. Benterki, N. Laouar, C. Bousbaa, N. Bouras, N. Bouaouadja, Influence of illuminating angle on scattered light caused by a sandblasted soda lime glass, Glass Technol.: Eur. J. Glass Sci. Technol. A., 53 (2012), 53-59

[18] ASTM G76-89, Standard practice for conducting erosion tests by solid-particle impingement using gas jets. ASTM, Philadelphia, 1992

[19] N. Adjouadi, N. Laouar, C. Bousbaa, N. Bouaouadja, G. Fantozzi, Study of light scattering on a soda lime glass eroded by sandblasting, J. Eur. Ceram. Soc., 27 (2007), 3221-3229 